\title{
PRESYSIBILITY CONCEPT OF PRE-PROPOSED MAJAPAHIT CITY, ON MODERN REGULATION OF AREA CASE STUDY ON CAMPUS UI, UB AND ITB
}

\author{
${ }^{1}$ Aloysius Baskoro Winarno. ${ }^{2}$ Dr. Ir. Yuswadi Saliya, M.Arch \\ ${ }^{1}$ Student in the Bachelor's (S-1) Study Program in Architecture \\ at Parahyangan Catholic University \\ ${ }^{2}$ Senior lecturer in the Bachelor's (S-1) Study Program in Architecture \\ at Parahyangan Catholic University
}

\begin{abstract}
Modern building design today has a tendency to focus only on the inner space, while the outer space only as space remaining from processing the space inside. Understanding of space in the context of modernwestern architecture is certainly not necessarily in harmony with the understanding of space in the context of traditional Javanese architectureBased on the ongoing activities in traditional Javanese buildings, it shows the composition of spatial arrangement that allows interaction with the environment so that it is sustainable and responsive to nature / climate. The mass of the building can be seen as the visual boundary of the space marker, so it can be processed, among others, by given certain pressures such as the use of ornamentation, etc. According to Professor of Southeast Asian Archaeological National University of Singapore John N. Miksic the power of Majapahit range includes Sumatra and Singapore and even Thailand as evidenced by the influence of culture, building style, temple, sculpture and art. Trowulan itself is the capital and civilization center of Java Majapahit. Nagarakretagama mentions the palatial culture of a noble and elegant, with delicate artistry and literature, as well as a complicated religious ritual system. Majapahit temples good quality geometrically by utilizing the sap of vines and brown sugar as a brick adhesive. This style of building can still be found in Java and Bali architecture. In addition, Trowulan has a reservoir system called "Segaran", which functions as flood control and water source during drought.

This research is trying to understand elements of ancient city of Trowulan and searching for the wealth of urban spatial Javanese - hindu this and looking for potential development in the present, The research will be done descriptively argumentative with qualitative approach through study on urban spatial Trowulan to modern area precedent.
\end{abstract}

Key Words: Urban Planning, Open Space, Majapahit Capital, Trowulan, Javanese- Hindu Civilization, Mandala

\section{PRESISTENSI KONSEP PENATAAN KOTA PRAINDUSTRI MAJAPAHIT, TERHADAP PENATAAN KAWASAN MODERN STUDI KASUS PADA KAMPUS UI, UB DAN ITB}

\author{
${ }^{1}$ Aloysius Baskoro Winarno. ${ }^{2}$ Dr. Ir. Yuswadi Saliya, M.Arch \\ ${ }^{1}$ Mahasiswa S1 Program Studi Arsitektur Universitas Katolik Parahyangan \\ ${ }^{2}$ Dosen Pembimbing S1 Program Studi Arsitektur Universitas Katolik Parahyangan
}

\begin{abstract}
Abstrak- Indonesia memiliki kekayaan arsitektur tradisional yang melimpah dan kontekstual dengan budaya lokal terkadang telah ditinggakan, seperti arsitektur tradisional Jawa. Perkembangan budaya di Jawa memiliki kedinamisan yang tinggi sehingga saat ini terlihat sudah mulai bergeser baik secara fisik maupun nilai-nilainya. Pemahaman ruang dalam konteks arsitektur modern-barat tentunya belum tentu selaras dengan pemahaman ruang dalam konteks arsitektur tradisional Jawa tersebut. Ruang-ruang arsitektur bangunan modern saat kini berkecenderungan dapat menghilangkan budaya guyub yang kental dalam tradisi Jawa dan membuat masyarakat menjadi lebih individual seperti tercermin dalam hunian-hunian golongan menengah ke atas. Kemaharajaan
\end{abstract}

\footnotetext{
${ }^{1}$ Corresponding Author: aloysius.baskoro@gmail.com
} 
Majapahit merupakan bukti pada masa klasik Asia Tenggara bahwa Nusantara pernah menjadi pusat peradaban melayu yang sangat berpengaruh. Beberapa elemen arsitektur berasal dari masa Majapahit, antara lain gerbang terbelah candi bentar, gapura paduraksa (kori agung) beratap tinggi, dan pendopo berdasar struktur bata. Gaya bangunan seperti ini masih dapat ditemukan dalam arsitektur Jawa dan Bali. Selain itu, Trowulan memiliki sistem waduk yang bernama "segaran", yang berfungsi sebagai kontrol banjir serta sumber air saat kemarau. Memang tidak bisa dipungkiri, Trowulan merupakan kawasan urban padat di tepi sungai brantas yang tersohor hingga negeri seberang.

Penelitian ini berusaha untuk memahami elemen elemen kota kuna Trowulan dan mencari kekayaan tata ruang kota jawa - hindu ini dan mencari potensi pengembangannya di masa kini, Penelitian akan dilakukan secara deskriptif argumentatif dengan pendekatan kualitatif melalui pengkajian pada tata ruang perkotaan Trowulan terhadap Preseden kawasan modern. Penelitian ini bertujuan menemukan kembali jejak jejak peradaban besar Indonesia sebagai Identitas bangsa.

Kata Kunci: Penataan fisik kota, Ruang Terbuka, Ibukota Majapahit, Trowulan, Peradaban Jawa Hindu, Mandala

\section{PENDAHULUAN}

Majapahit merupakan kemaharajaan bahari yang kekuasaanya hampir meliputi sebagian besar asia tenggara. Kerajaan yang terdiri dari wilayah inti, mancanagara serta nusantara ini juga memiliki hubungan dengan mitteka satata (atau kerajaan lain) atau dapat disebut aliansi Majapahit (Ayyutahya, Champa, Nakhon, Sinhanagari, dan kerajaan lain di Asia tenggara).

Trowulan terletak di kecamatan trowulan, Kabupaten Mojokerto Jawa Timur. Banyak catatan yang mengatakan bahwa ibukota ini merupakan kota yang makmur dan tertata. Uraian Nagarakretagama tentang Kota Majapahit telah dicari lokasinya di lapangan oleh Maclains Pont pada tahun 1924-1926. Ia berhasil membuat sketsa "kota" Trowulan di Situs Trowulan. Benteng kota Majapahit digambarkan dalam bentuk jaringan jalan dan tembok keliling yang membentuk blok-blok empat persegi.

Secara makro, bentuk Kota Trowulan menyerupai bentuk mandala candi berdenah segi empat dan terdapat gapura masuk di keempat sisinya, sedangkan keraton terletak di tengah-tengah. Selain itu terdapat kediaman para punggawa dan prajurit, pejabat pemerintah pusat, (seperti para menteri), pemimpin keagamaan/ dhammayaksa, para kesatria, lapangan besar (seperti:paseban, lapangan Bubat), kolam segaran, tempat pemandian, dan lain-lain.

Menurut Prapanca dalam kitab Negarakertagama; keraton Majapahit dikelilingi tembok bata merah yang tinggi dan tebal. Di dekatnya terdapat pos tempat para punggawa berjaga. Gerbang utama menuju keraton (kompleks istana) terletak di sisi utara tembok, berupa gapura agung dengan pintu besar terbuat dari besi berukir. Di depan gapura utara terdapat bangunan panjang tempat rapat tahunan para pejabat negara, sebuah pasar, serta sebuah persimpangan jalan yang disucikan.

Lokasi yang merupakan bekas kota kerajaan Majapahit terdapat di Trowulan Mojokerto. Lingkungan alam di sekitar situs trowulan yang terletak di lembah Brantas hilir, sangat potensial untuk mendukung kehidupan perkotaan. Bentang alam yang datar dan luas memberi kemungkinan pengembangan lahan permukimkan kota. Masa kejayaan Majapahit terjadi pada masa pemerintahan Hayam Wuruk, yang dinobatkan pada tahun 1350, dengan gelar Sri Rajasanagara. Sebagian masa pemerintahannya, Hayam Wuruk didampingi oleh Patih Gajah Mada. .

\section{UNSUR-UNSUR KOTA MAJAPAHIT}

Menurut Hermanislamer (1999), terdapat data data tafsiran tentang keruangan kota majapahit yang dilakukan beberapa peneliti masa lampau. Peneliti tersebut yaitu: Maclaine 
Pont (1924), Stutterheim (1948), Pigeaud (1960) serta Slametmulyono (1976). Dari 4 ahli tersebut, terdapat kesamaan dalam menafsirkan kedudukan unsur unsur kota terhadap orientasi kompas, peletakan istana raja, detail 3 istana, zonasi, lokasi kedharmadhyaksaan serta rumah rumah bangsawan lainnya. Pada penempatan unsur-unsur jaringan jalan, perempatan jalan dan jaringan prasarana air, dalam kaitannya dengan unsur unsur kota lainnya terdapat perbedaan.

Oleh karena itu, diperlukan metode overlay terhadap peta peta tersebut, serta peta pengindraan undara terbaru (lewat Bakorsutanal) untuk mencapai temuan yang lebih akurat:

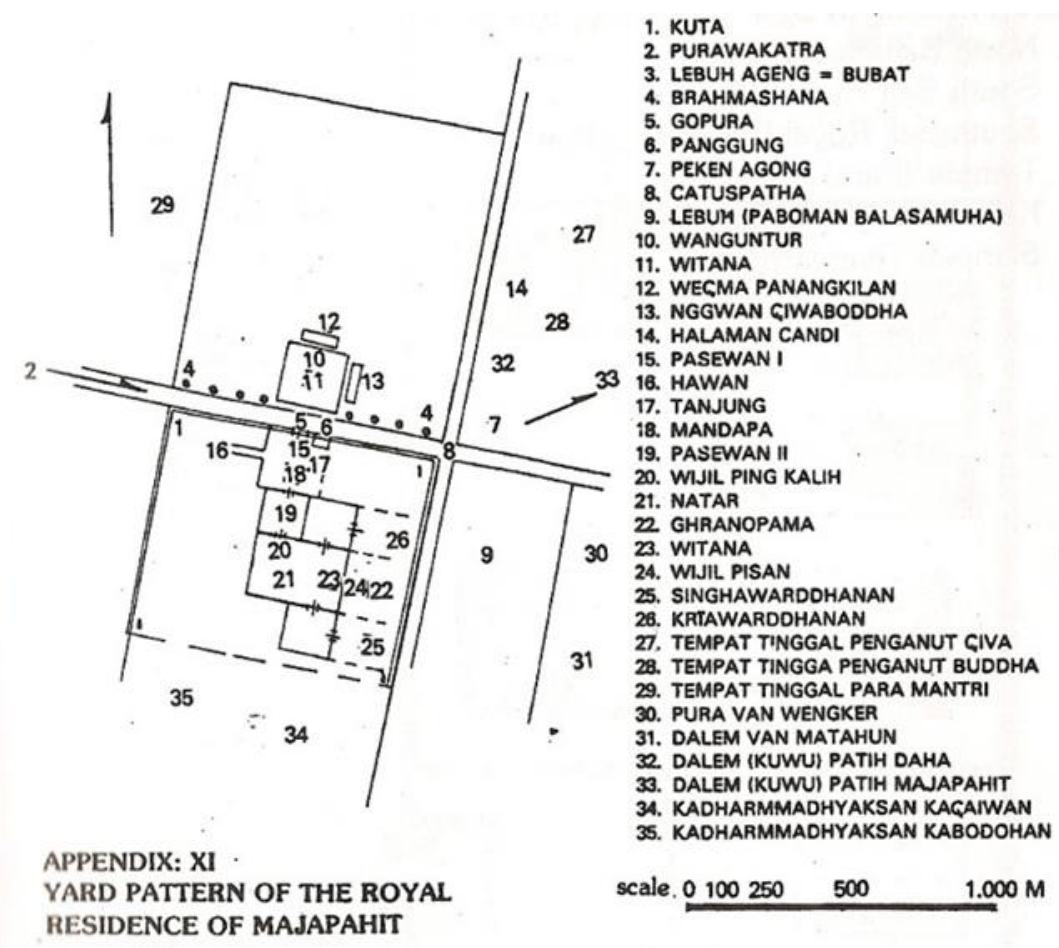

From: De Kraton van Majapahit, Stutterheim, 1949, page 124

Figur 1. Interpretas Peletakan berdasarkan kitab Negarakertagama Sumber: Stuterheim 1948

Unsur unsur keruangan kota kerajaan majapahit dapat ditemukenali melalui data data peneliti sebelumnya serta elaborasi terhadap kitab silpasastra. Unsur unsur kota Majapahit tersebut antara lain: (1) Dinding, (2) Gapura, (3) Lapangan Umum Kota, (4) Balai Pertemuan Umum, (5) Pasar, (6) Bangunan Suci \& Tempat Sesaji, (7) Kraton/Istana Raja, (8) Kepatihan/Tempat Tinggal Raja, dan (9) Tempat Tinggal Rohaniwan.

Dinding. Kota Majapahit bukan kota berdinding, hanya kraton nya saja yang berdinding. Hanya kraton yang berdinding karena didasari alasan filsafat yang kuat: sifat terbuka bagi para warganya, sedangkan dinding hanya fungsional untuk perlindungan petinggi petinggi kerajaan. Kerajaan jawa cenderung memilih alasan filsafat, diding dan pagar dibangun untuk menjadi batas hak milik atau privasi.

Gapura. Gapura dipandang sebagau pagar/ dinding suatu kawasan (kota, kampus) ataupun sebuah halaman tempat tinggal. Ia dipandang sebagai celah 'resmi' pada dinding kota. Tempat keluar masuk secara resmi dan seremonial. Untuk kota tanpa pagar, gapura dipandang sebagai symbol

Prasarana Jalan kota dan Saluran Air. Gapura dipandang sebagau pagar/ dinding suatu kawasan (kota, kampus) ataupun sebuah halaman tempat tinggal. Ia dipandang sebagai celah 
'resmi' pada dinding kota. Tempat keluar masuk secara resmi dan seremonial. Untuk kota tanpa pagar, gapura dipandang sebagai symbol.

Lapangan Umum Kota. Temuan lapangan berupa hasil interpretasi foto udara memberikan gambaran adanya pola papan catur (grid) yang terbentuk oleh jaringan prasarana yang saling berpotongan secara bersilangan tegak lurus. Sehingga berdasarkan analisa kemudian, jalur ini disimpulkan sebagai jalur jalan utama, berpotongan secara tegak lurus utara-selatan timurbarat, yang berpola papan catur

Balai Pertemuan Umum. Berfungsi sebagai balai pertemuan petinggi kerajaan. Terletak di sebelah utara luar kraton.

Pasar. Penemuan proselen porselen merupakan bukti satu satunya keberadaan pasar di Trowulan

Bangunan Suci \& Tempat Sesaji. Terdapat tempat ibadah Siwa dan Buddha. Terletak di timur laut kraton. Demikian pula dengan lapangan dan tempat sesajen.

Kraton/ Istana Raja. Pola penataannya berupa grid, peletakannya juga terdapat di sekitar kolam segaran (Pigeaud). Jika kawasan kota dibagi menjadi 4 kuadran, maka kompleks kraton berada di barat dan barad daya. Kompleks kraton terdiri dari 3 lapis halaman dan 3 gapura. Didalamnya terdapat pula 3 tempat tinggal: Raja, serta dua saudaranya.

Kepatihan/Tempat Tinggal Raja. Terdapat rumah dari patih Gajahmada, Bre Wengker dan lainnya. Terdapat di sebelah utara dan timur laut kraton. Jika ditelaah dari organigram Majapahit, maka tempat ini bisajadi merupakan tempat tinggal para Rakyan Mantri ri Pakirakiran

Tempat Tinggal Rohaniwan. Merupakan tempat bernama "Kedharmmayaksaan". Dharmmayaksa atau pemuka agama merupakan bawahan daripada rakyan mantra.

Rekonstruksi keruangan kota Majapahit dilakukan berdasarkan pemikiran sistemik dan keseluruhan (wholeness). Majapahit dianggap sebagai suatu system keruangan utuh, terdiri atas unsur unsur keruangan (spasial) dan nirkeruangan . Berdasarkan Overlay dari peta peta

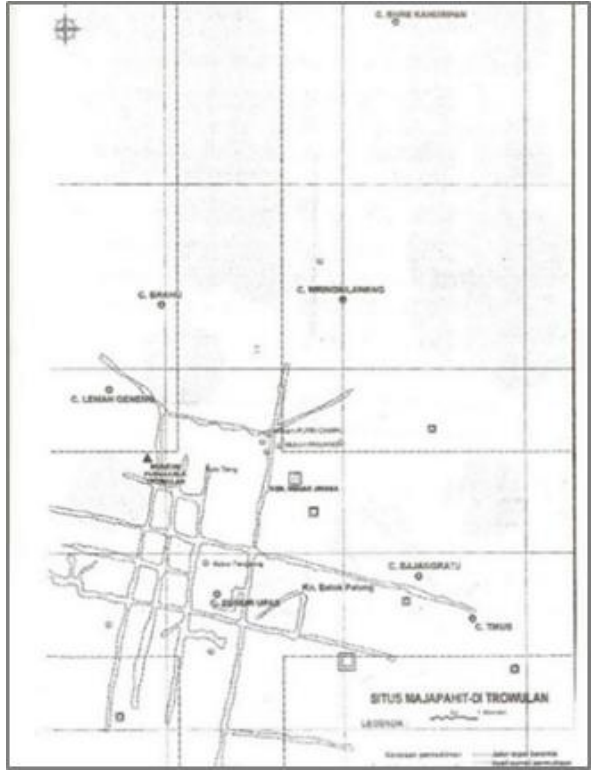

Figur 2. Hasil Overlay Peta

Sumber: Hermanislamet, B. 1999. Tata Ruang Kota Majapahit

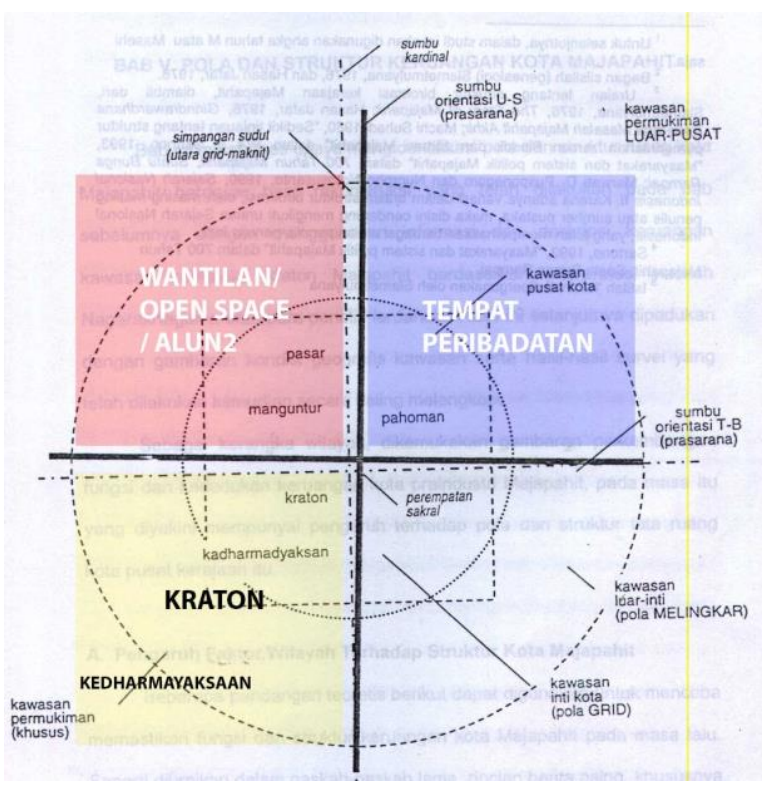

Figur 3. Konsep Perempatan agung Sumber: Hermanislamet, B. 1999. Tata Ruang Kota Majapahit 
Model Struktur Keruangan, ini merupakan diagram hasil keterkaitan antara heirarki/organigram kerajaan dengan penataan kawasan kota. Berdasarkan hubungan organigram Majapahit dengan Kampus.

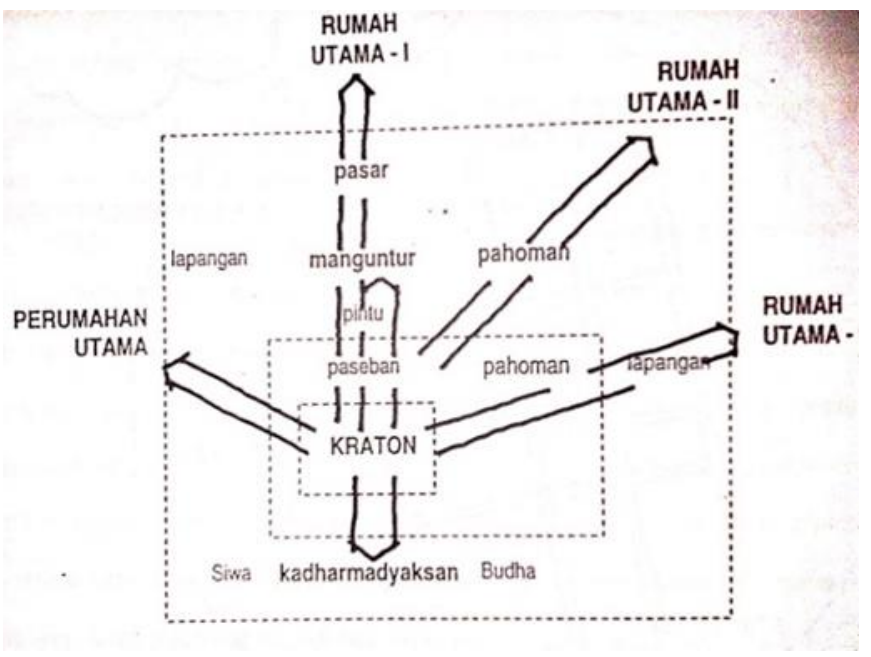

Figur 4. Model Struktur Keruangan Kota Sumber: Hermanislamet, B. 1999. Tata Ruang Kota Majapahit

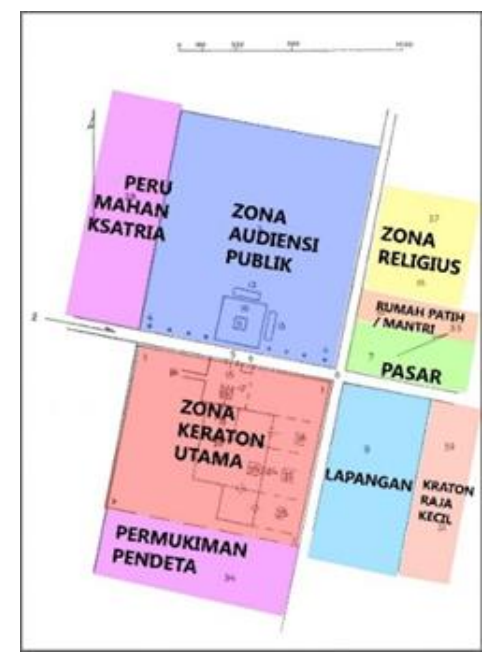

Figur 5. Zonasi pada Trowulan Sumber: Hermanislamet, B. 1999. Tata Ruang Kota Majapahit modifikasi penulis

\subsection{ELEMEN CITRA KOTA MAJAPAHIT}

Citra kota merupakan kesan fisik yang memberikan ciri khas kepada suatu kota. Dalam pengembangan suatu kota, citra kota berperan sebagai pembentuk identitas kota, dan sebagai penambah daya tarik kota. Oleh karena itu, citra kota yang jelas dan kuat akan memperkuat identitas dan wajah kota sehingga membuat kota tersebut menarik dan memiliki daya tarik. Citra kota dapat dibuat secara instan, sedangkan identitas membutuhkan waktu yang lama untuk membentuknya, karena citra kota belum tentu merupakan identitas. Jati diri kota berkaitan dengan ritme sejarah yang telah melalui proses panjang sehingga jati diri suatu kota tidak dapat diciptakan begitu saja berbeda dengan citra kota.

Tabel 1. Prasarana yang Memenuhi dan yang Tidak Memenuhi Standar

\begin{tabular}{|l|l|l|}
\hline Elemen Citra & Kasil & $\begin{array}{l}\text { Keterangan } \\
\text { PATH 2 Jalan Primer } \\
\text { Jalan paling lebar } \\
\text { S Sirkulasi utama masuk- keluar }\end{array}$
\end{tabular}




\begin{tabular}{|c|c|c|}
\hline Elemen Citra & Hasil & Keterangan \\
\hline EDGES & 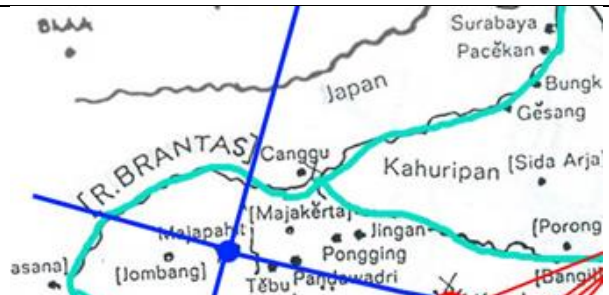 & $\begin{array}{l}\text { - Penghalang/ barrier } \\
\text { - Batas suatu distrik } \\
\text { - Gunung/ Bukit= Penanggungan } \\
\text { - Sungai, Bluescape= Segaran \& } \\
\text { Kali Brantas } \\
\text { - Pepohonan/ Hutan/ Green belt= } \\
\text { Hutan Tarik, Hutan Maja }\end{array}$ \\
\hline NODE & s3 & $\begin{array}{l}\text { - } \text { Mercu Tempat tinggi (Bukit) } \\
\text { - Mercu Tempat tertinggi } \\
\text { (Gunung) } \\
\text { - Sumber air } \\
\text { - Laut (profan) } \\
\text { - Tanda Geografis Lain }\end{array}$ \\
\hline $\begin{array}{l}\text { LANDMARK } \\
\text { ALAM }\end{array}$ & NISTA = LAUT JAWA & $\begin{array}{l}\text { - } \text { Mercu Tempat tinggi (Bukit) } \\
\text { - Mercu Tempat tertinggi } \\
\text { - } \text { (Gunung) } \\
\text { - Sumber air } \\
\text { - Laut (profan) } \\
\text { - Tanda Geografis Lain }\end{array}$ \\
\hline
\end{tabular}




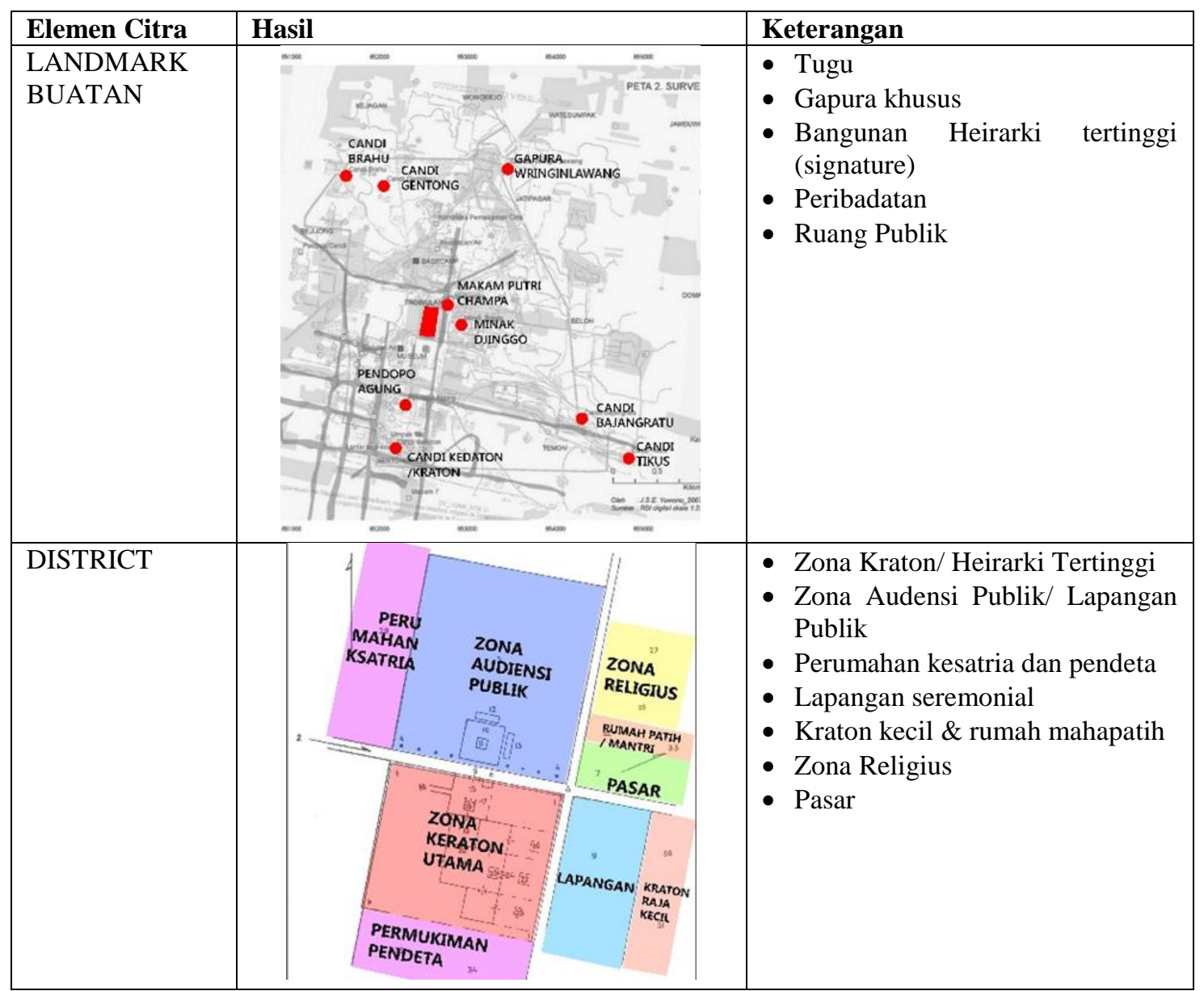

Pada data unsur keruangan pusat kota, unsur keruangan kota majapahit dan model sturktur keruangan kota dapat dilihat pada penelitian versi lengkapnya, karena bersifat data des study.

\section{PERSAMAAN ELEMEN UNSUR CITRA KOTA ANTARA MAJAPAHIT DAN KAMPUS}

\subsection{KAMPUS UNIVERSITAS INDONESIA}

Berikut merupakan rekapitulasi tabel analisa 2 yang dinilai berdasarkan keyword (serupa, serupa parsial, ada, ada parsial, tidak ada).

Tabel 2. Persamaan Elemen Unsur Cintra Kota antara Majapahit dan Kampus Universitas Indonesia

\begin{tabular}{|c|c|c|c|c|}
\hline No & Unsur Bahasan & Keyword & Skor & Keterangan \\
\hline \multicolumn{4}{|c|}{ Komparasi Elemen Citra Kota / Kawasan } \\
\hline 1 & Path & Ada parsial & 1 & \\
\hline 2 & Edges Natural & Ada & 2 & \\
\hline 3 & Edges Man Made & Ada & 2 & \\
\hline 4 & Landmark Natural & Serupa & 4 & \\
\hline 5 & Landmark Man Made & Ada & 2 & \\
\hline 6 & Node & Ada parsial & 1 & \\
\hline 7 & District & Serupa parsial & 3 & \\
\hline & Subtotal: & & $\mathbf{1 5}$ & \\
\hline
\end{tabular}


Pada Kampus UI, Elemen yang sangat Serupa adalah Landmark Natural dan Distrik. Landmark Natural mengacu pada gunung salak sebagai landmark sacral, dan laut jawa sebagai profane/ nista. Pada Distrik, pembagiannya cukup serupa dengan Trowulan, karena terdapat padanan yang sama, seperti: Pendidikan: perumahan ; Komersial: pasar; Religious: masjid ; Rekreasi: audensi; serta Plaza rektorat: lapangan.

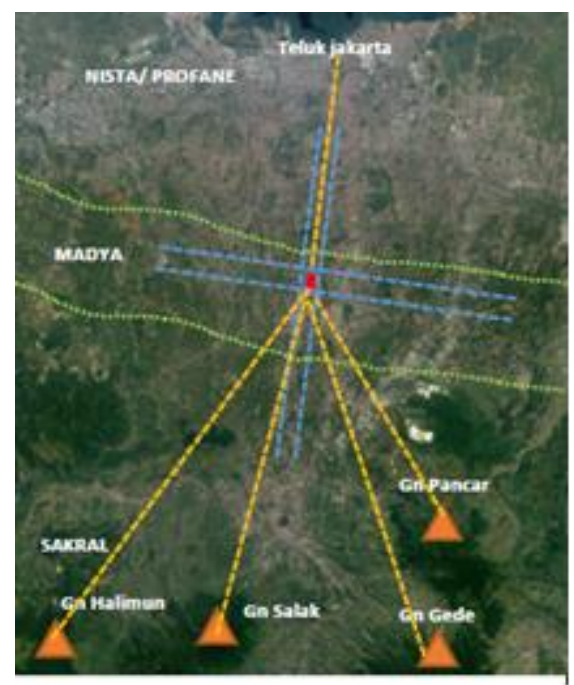

Figur 6. Landmark Alam

Sumber: Google Earth, diakses maret 2017

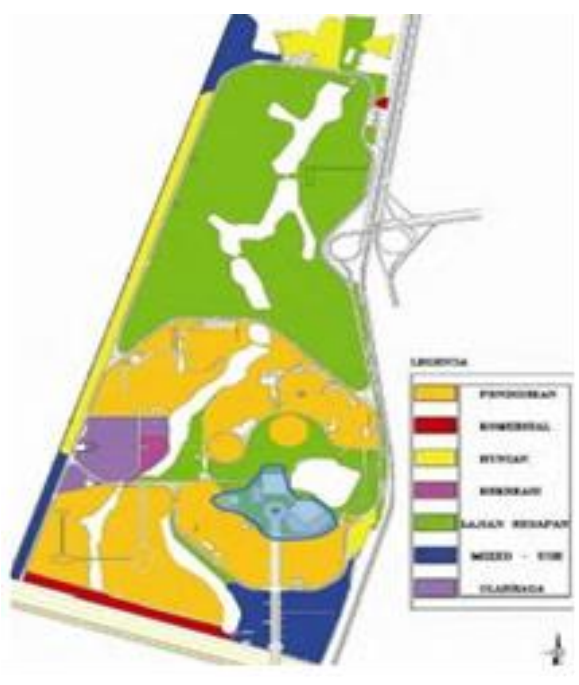

Figur 7. Distrik dan Zonasi

Sumber: http://perpustakaan.bappenas.go.id/lontar

\subsection{KAMPUS UNIVERSITAS BRAWIJAYA}

Berikut merupakan rekapitulasi tabel analisa 2 yang dinilai berdasarkan keyword (serupa, serupa parsial, ada, ada parsial, tidak ada).

Tabel 3. Persamaan Elemen Unsur Cintra Kota antara Majapahit dan Kampus Universitas Brawijaya

\begin{tabular}{|c|c|c|c|c|}
\hline No & Unsur Bahasan & Keyword & Skor & Keterangan \\
\hline \multicolumn{2}{|c|}{ Komparasi Elemen Citra Kota / Kawasan } & \\
\hline 1 & Path & Serupa & 4 & \\
\hline 2 & Edges Natural & Serupa & 4 & \\
\hline 3 & Edges Man Made & Ada & 2 & \\
\hline 4 & Landmark Natural & Ada & 2 & \\
\hline 5 & Landmark Man Made & Ada & 2 & \\
\hline 6 & Node & Serupa & 4 & \\
\hline 7 & District & Serupa & 4 & \\
\hline & Subtotal: & & $\mathbf{2 2}$ & \\
\hline
\end{tabular}

Pada Kampus UI, Elemen yang sangat Serupa adalah Path, Edges Natural, Node serta distrik. Hal ini dikarenakan tatanan sirkulasi yang grid, serta pengadopsian usnur trowulan yang konsisten, seperti: perempatan agung sebagai node, serta distrik yang direncanakan. 


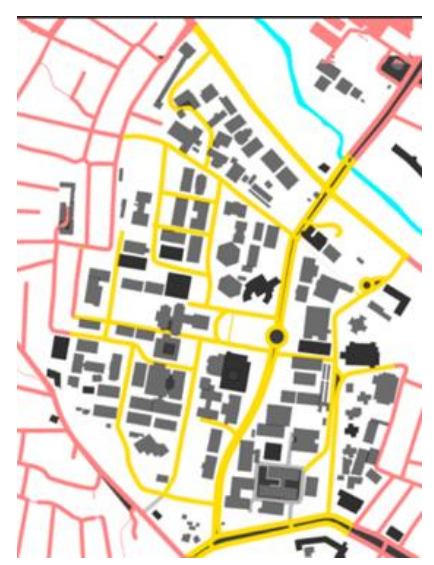

Figur 8. Path yang membentuk Grid Sumber: Google Earth, diakses maret 2017

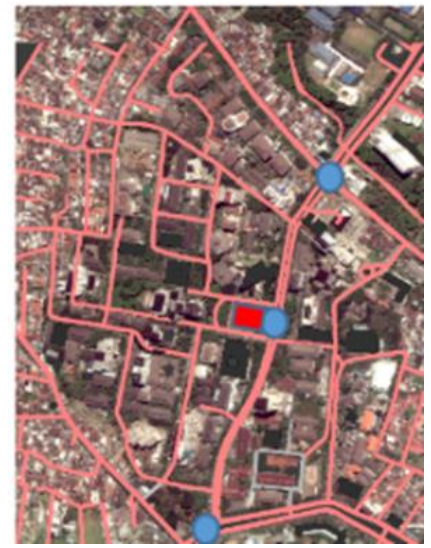

Figur 9. Node Sumber: Google Earth, diakses maret 2017

\subsection{Kampus Institut Teknologi Bandung}

Berikut merupakan rekapitulasi tabel analisa 2 yang dinilai berdasarkan keyword (serupa, serupa parsial, ada, ada parsial, tidak ada).

Tabel 4. Persamaan Elemen Unsur Cintra Kota antara Majapahit dan Kampus Institut Teknologi Bandung

\begin{tabular}{|l|l|l|l|l|}
\hline No & Unsur Bahasan & Keyword & Skor & Keterangan \\
\hline \multicolumn{2}{|l|}{ Komparasi Elemen Citra Kota / Kawasan } & 4 & \\
\hline 1 & Path & Serupa & 4 & \\
\hline 2 & Edges Natural & Serupa & 4 & \\
\hline 3 & Edges Man Made & Ada & 2 & \\
\hline 4 & Landmark Natural & Serupa parsial & 3 & \\
\hline 5 & Landmark Man Made & Serupa & 4 & \\
\hline 6 & Node & Serupa parsial & 3 & \\
\hline 7 & District & Ada & 2 & \\
\hline & Subtotal: & & 22 & \\
\hline
\end{tabular}

Pada Kampus ITB, Nilai tinggi diraih oleh Path, Edges Natural, dan Landmark Man made. Hal yang paling menonjol adalah path dan landmark, dimana path membentuk persimpangan node, dengan tugu ditengah. Persimpangan ini sarat dengan persimpangan agung.

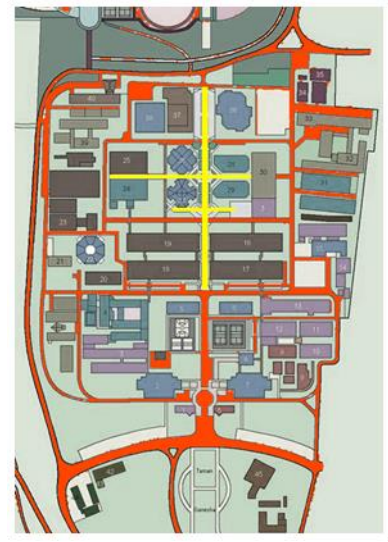

Figur 10. Path yang membentuk Grid Sumber:

https://bangkamil.wordpress.com/2008/08/19/keajaibankeunikan-itb//, diakses april 2017)

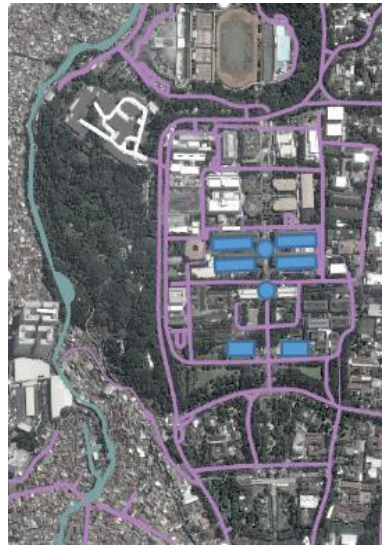

Figur 11. Landmark Sumber: Google Earth, diakses maret 2017) 


\section{PEMBAHASAN}

\subsection{PEMBAHASAN KAWASAN KAMPUS UNIVERSITAS INDONESIA}

Seperti yang sudah dijabarkan sebelumnya, kampus UI mendapat skor 68.1\%. Hal yang dapat diperhatikan dari hasil ini adalah Tatanan yang tidak Grid. Oleh karena itu, skor untuk path dan konfigurasi jalan rendah. Selain itu, unsur perempatan agung juga sangat lemah di kawasan ini. Hal ini dikarenakan sirkulasi/ jalan utama kampus, justru berbentuk melingkar dan loop. Pertemuan jalan/ persimpangan terdapat di beberapa pertigaan/ junction yang bukan berupa perempatan. Sedangkan sirkulasi di bagian centrum, berbentuk melingkar mengeliling kawasan pusat. Hal ini sangat tidak bisa dipaksakan dan disamakan terhadap Kota Majapahit.

Namun, unsur pusat kota yang berkaitan dengan heirarki cukup merepresentasikan penataan Trowulan. Hal ini dikarenakan bangunan pusat kota yang fungsinya dikaitkan dengan heirarki organigram UI, yang kemudian dipadankan ke heirarki organigram Trowulan, hasilnya cukup identik. Pertama, rektorat (sebagai representasi kraton) memiliki inner court, serta berada di kawanan yang dinamakan "centrum".

Kedua, pada kawasan centrum ini, terdapat bangunan yang memiliki fungsi dengan heirarki dibawah rekorat (teratas kedua, ketiga). Fungsi yang dimaksud adalah: Kraton, pusat arsip/ administrasi dan perpustakaan. Selain itu, balairung atau tempat pertemuan juga terdapat di area centrum (timur rektorat).

Ketiga, karena kawasan UI merupakan kawasan kampus yang paling luas, maka tiap fakultas dikumpulkan dalam bentuk tatanan cluster. Kelompok bangunan Fakultas adalah bangunan yang padanan heirarkinya adalah kepatihan dan pejabat agama. Peletakan fakultas dan rumah pejabat agama memiliki kemiripan dalam hal "terpisah dari kraton majapahit", meskipun peletakannya tidak serupa dengan Kota Majapahit.

\subsection{PEMBAHASAN KAWASAN KAMPUS UNIVERSITAS BRAWIJAYA}

Berdasarkan rekapitulasi skor, UB mendapat skor $82 \%$. Merupakan skor yang tinggi, dikarenakan hamper semua aspek mendapat nilai sempurna. Hal ini dikarenakan setiap unsur yang dibahas dan diidentifikasikan, ternyata memiliki tata letak yang serupa denga tata letak kota Majapahit menurut Sttuterheim. Keserupaan peletakan berdampak signifikan dengan perolehan skor. Contohnya saja pada pembahasan perempatan agung. Unsur unsur perempatan agung tidak hanya sebatas "ada", namun peletakan berdasarkan arah dan mata angin antara kedua objek ini begitu serupa. Jika dideskripsikan, dari timur perempatan terdapat rektorat (kraton), lalu secara arah jarum jam diikuti oleh Gedung serbaguna: Widyaloka (Balai Wanguntur), bank BRI (Pasar), Masjid, Lapangan (Bubat, Pahoman), serta bangunan administrasi penunjang rektorat.

Pada Unsur keruangan kota, perbedaan antar kedua kawasan terdapat di paseban, karena Kampus UB tidak memiliki paseban, dan hanya memiliki sedikit open spaces. Unsur lapangan bubat pun juga ditak dimilki oleh UB, meskipun secara fungsi digantikan oleh Gedung Widyaloka. Lokasi peribadatan pun serupa dengan trowulan, hanya saja akses ke tempat ini tidak melewati jalan utama. Meskipun ada akses manusia dari jalan utama, namun bangunan masjid tidak dibangun di depan jalan utama. Hal ini kemungkinan dikarenakan akan menghadap ke bagian belakang masjid, jika dipaksakan dibangun di jalan utama. Pada Model struktur keruangan kota, kawasan kampus ini mendapat nilai sempurna. Karena konsep pembagian fungsi heirarki yang konsentris dan konsisten menerapkan konsep kota 
majapahit (berdasarkan wawancara). Tatanan grid yang kuat, serta area pusat kawasan yang kuat, juga menjadi nilai lebih bagi kampus ini.

\subsection{PEMBAHASAN KAWASAN KAMPUS INSTITUT TEKNOLOGI BANDUNG}

Pada kampus ITB, Meskipun mendapatkan skor yang rendah, namun temuan anomaly cukup banyak disini. Jika berdasarkan wawancara, pengembangan kampus UTB tidak didasari oleh Trowulan, namun nyatanya tim pembangunan selalu melakukan repetisi pada unsur perempatan di kawasan ini. Unsur perempatan pada pusat sangat sarat dengan kota hindu, bukan kota islam.

Perempatan yang diulang ulang inilah yang agak memberikan makna ganda untuk menemukan pusat kawasan ini sesungguhnya. Meskipun path dan tatanan sudah berbentuk grid, tapi tidak bisa mendongkrak skor dari kawasan ini. Salah satu hal yang paling fatal dalam perencanaan itb adalah terpisahnya rektorat dengan kawasan kampus ganesha. Hal ini sangat tidak merepresentasikan konsep trowulan yang kuat pada unsur pusat kotanya (perempatan agung), meskipun fungsi rektorat pernah diletakkan di barakgebouw (aula itb), namun perkembangan kampus selanjutnya yang malah memisahkan rektorat dengan kampus ganesha. Selain itu, unsur unsur heirarki yang lain juga tidak mencerminkan pembagian yang konsisten secara keseluruhan. Hal ini dikarenakan tidak ada pembagian wilayah fakultas yang jelas, dan fungsi ini ditampung secara fleksibel pada bangunan bernama Labtek. Meskipun pasti ada pembagian gedung, namun penataannya tidak pasti dan kemungkinan besar tidak direncanakan matang matang.

Namun unsur perempatan ini merupakan warisan yang berharga dari Mclaine Pont, karena menjadi inti aktivitas tiap civitas kampus. Hal ini juga berpengaruh pada model sturktur keruangan kawasan, meskipun tanpa pusat yang jelas. Jika dikaji lebih dalam lagi, kemungkinan bisa dipilih perempatan pusat daripada pusat. Untuk sementara ini, penulis menduga, perempatan di jalan ganesha merupakan perempatan pusat, karena terdapat unsur kompleks keagamaan dan masjid salman di tenggara perempatan, dan terdapat komersial (bank). Kemungkinan juga, perempatan agung pusat adalah plaza widya mandala, karena merupakan wilayah tengah kawasan ini.

\section{KESIMPULAN PRESISTENSI}

Berdasarkan data dan analisis terhadap Kesamaan Unsur Citra Kota, Perempatan Agung, Unsur Keruangan Kota dan Model Struktur keruangan kota, pada 3 kawasan kampus: UI, UB dan ITB, maka dapat diberi kesimpulan akhir dalam bentuk urutan kampus mana yang paling menerapkan konsep Trowulan/ Kota Majapahit secara konsisten.

Perolehan hasilnya adalah: Universitas Brawijaya (Rancangan Ali Sukirno \& Tim) dengan Skor $87 \%$ mendapat urutan pertama, karena dinilai penulis paling mengadopsi unsur unsur trowulan secara simbolis maupun fungsional.

Urutan berikutnya diberikan kepada Kampus Universitas Indonesia (Rancangan Budi Sukada dan Gunawan Tjahjono). Meskipun pengakuan konsep hanya pada rektorat, namun secara konsisten kawasan UI menerapkan prnsip prinsip dasar kota majapahit, seperti: Centre and Periphery, hairarki tertinggi serta tatanan grid (pada bangunannya).

Sedangkan urutan terakhir diberikan pada Kampus ITB Ganseha (Rancangan Mclaine Pont, Slamet Wirasonjaya, Eko Purwono dan tim), yang memang berkembang tanpa prinsip Trowulan. Meskipun warisan masterplan MclainePont terus diterapkan pada perempatannya, namun tidak bisa menguatkan bukti yang sahih bahwa ada unsur majapahit di kampus ini. Meskipun begitu, terdapat temuan temuan menarik tentang kampus ini, disinyalir sebagai catata satu satunya yang mungkin bisa dikembangkan di kemudian hari, tentang unsur Majapahit yang tersembunyi di kampus ITB. 


\section{TEMUAN}

Walaupun beberapa objek tidak mendapat hasil yang positif sesuai hipotesa. Berikut temuan yang mungkin dapat dilanjutkan ke penelitian tahap atau jenjang berikutnya.

a. Terdapat Pengulangan Unsur Perempatan agung yang sebelumnya direncanakan oleh Mclaine Pont.

b. Ada konsistensi pemberian unsur perempatan di setiap pembangunan kampus ITB, hal ini disampaikan langsung oleh bapak Eko Purwono. Mungkin bisa menjadi anomaly keberadaan konsep majapahit, meskipun tidak ada saksi hidup yang mengakui konsep terebut

c. Kota Majapahit merupakan bukti peradaban besar bangsa Indonesia yang sedikit tersisa di tanah jawa. Kesulitan dalam pencarian Informasi yang valid menjadi kendala penulis dalam mempelajari penataan kota Trowulan. Hal ini bisa menjadi batu loncatan awal untuk menggalakan penelitian massif terstruktur oleh pelaku arkeolok dan arsitek.

d. Kota majapahit mempengaruhi perkotaan Islam setelahnya, dan ternyata konsistensi konsep tersebut tetap bisa dterapkan pada perencanaan kawasan modern. Ada kemungkinan besar terdapat pemikiran simbolis agama yang dihubungkan dengan pemikiran fungsional, dan ternyata melebur saling simbiosis satu sama lain. Hal ini merupakan sesuatu yang luar biasa, karena jika digali lebih dalam, akan mengangkat penemuan penemuan orang orang asia, dengan menemukan pedoman tata kota menurut kerajaan Majapahit.

\section{PENUTUP}

Pada akhir penelitian ini, peneliti mengharapkan agar suatu saat topik ini dapat dilanjutkan. Kita perlu mengetahui lebih banyak tentang kota kota Hindu - Buddha, karena pada masa itulah, bangsa kita menjadi bangsa maju dan berpengaruh di Asia Tenggara. Pencarian arkeologis dan arsitekur harus lebih rajin dilakukan untuk menemukan jati diri bangsa kita, lewat teknologi penataan kota. Terdapat kota kota Hindu Buddha, yang sampai saat ini belum di temukan, seperti: Kota Mataram Kuno, Kota Sriwijaya, dan lainnya. Jika benar benar ditemukan, studi untuk penataan kota hindu- Buddha dapat dilakukan dan dapat dilestarikan pada penataan kawasan di kemudian hari.

\section{DAFTAR PUSTAKA}

Ambarwati, Dwi Retno Sri (2007), Relevansi Vastushastra dengan Konsep Perancangan

Joglo Yogyakarta, Fakultas Bahasa dan Seni Universitas Negeri Yogyakarta

Amrit Gomperts, Arnoud Haag and PeterCarey. 2008. Stutterheim's enigma:The mystery of his mapping of the Majapahit kraton at Trowulan in 1941 . Koninklijk Instituut voor Taal-, Landen Volkenkunde

De Vries, Gerrit; Howeleer, DS. (2009) Hendri Maclaine Pont: Architect, Constructeur, Archeoloog. Rotterdam: vormgeving Manifesta

Hermanislamet, Bondan (1999). Tata Ruang Kota Majapahit, Analisis Keruangan Pusat Kerajaan Hindu Jawa Abad XIV di Trowulan Jawa Timur. Disertasi, Tidak dipublikasikan. Yogyakarta: Universitas Gadjah Mada

Harbraken.N.J..(1998), The Structure of the Ordinary, Form and Control in the Built

Environment, London: The MIT Press, Cambridge, Massachusetts -

Ismudiyanto, Pramono Atmadi (1987). Demak, Kudus, Jepara Mosques, a Study of Architectural Syncretism. Yogyakarta: Universitas Gadjah Mada.

Lynch, Kevin (1960), Image of The City, the Massachusetts Institute of Technology 
Pigeaud, Theodore G. 1960, Java in the $14^{\text {th }}$ Century. The Hague: Martinus Nijhoff

Rahadhian PH, Elfan Kedmon (2009). A Study of the Pattern of the Classical City Centre on Java:Transformation and Duality, The Legacy of the Hindu-Majapahit and IslamicMataram Eras. Semarang: Universitas Diponegoro

Rahardian, PH; Richard, Antonius; Wibawa, Ferry (2014), Kajian Tipomorfologi

Arsitektur Percandian 'Kayu'di Jawa. Bandung: LPPM Unpar

Rahardian, PH (2011), Representasi Candi Dalam Dinamika Arsitektur Era Pasca Kolonial di Indonesia, Disertasi, Bandung: Unpar

Ma Huan. Yingyai Shenglan. Terjemahan J.V.G. Mills. Cambridge, 1970.

Muchamad, BN (2011). Analisis Tipomorfologi Sebagai Pendekatan Perencanaan

Terhadap Ancaman Bencana di Kota Banjarmasin. Paper, Samarinda: Universitas Lambung Mangkurat

Stutterheim, W.F.1948. De Kraton Van Majapahit. S-Gravenhage: Martinus Nijhoff

Van Leerdam, Ben f . 1988. Hendri Maclaine Pont, Architect tussen twee werelden. Delfte Universitaire Pers 